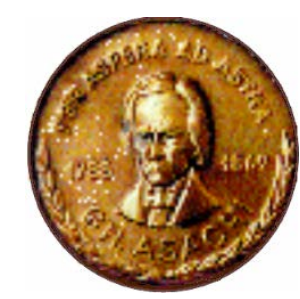

\title{
TOWARDS THE OPTIMAL DESIGN AND OPERATION OF MULTI-ENERGY SYSTEMS: THE “EFFICITY” PROJECT
}

\author{
Matteo Zatti ${ }^{1,2}$, Marco Gabba ${ }^{2}$, Michele Rossi ${ }^{3}$, Mirko Morini ${ }^{4}$, \\ Agostino Gambarotta ${ }^{4}$, Emanuele Martelli ${ }^{1 *}$ \\ ${ }^{1}$ Politecnico di Milano, Department of Energy, Via Lambruschini 4 - 20133, Milano, Italy \\ ${ }^{2}$ Energy \& Environment Laboratory Piacenza, Via Nino Bixio 27/c - 29121, Piacenza, Italy \\ ${ }^{3}$ SIRAM, Milano, Italy \\ ${ }^{4}$ University of the Studies of Parma, Interdepartmental Center for Energy and the Environment, \\ Parco Area delle Scienze, 181/a - 43124, Parma, Italy
}

\begin{abstract}
The development of Multi-Energy Systems (MES) or District Energy Systems (DES) requires suitable design and operation optimization tools, in order to assess their feasibility and economic profitability. These tools can be helpful in choosing the proper technologies and also in the perspective of defining proper incentive or taxation schemes. A critical result of the analysis of MES is that, when optimizing their design, the operation strategy and the part load behavior of the units must be considered in the optimization model. This way, the model is to be formulated as a two-stage problem, where the design and the operation variables are optimized in the first and in the second stage, respectively. In order to guarantee the computational tractability, the scheduling/operation problem is solved for a limited set of typical and extreme periods. We have developed a Mixed Integer Linear Programming model to solve this design optimization problem, for which we have linearized the off-design and the size effects of performances and costs for the technologies considered in the case study. The model has been applied to optimize the design of a district energy system for the University of Parma Campus in Northern Italy.
\end{abstract}

Key words: carbon tax, design optimization, district energy systems, tri-generation

Received: March, 2018; Revised final: July, 2018; Accepted: September, 2018; Published in final edited form: October 2018

\section{Introduction}

Multi-Energy Systems (MES) and DistrictEnergy Systems (DES) have been considered as promising solutions to lower the costs and the environmental impact of the energy production, distribution and use in urban areas (Weber et al., 2007). The fundamental concept is the integration of the energy networks - i.e. electricity, heating and cooling - operating in residential, commercial and industrial districts, so as to maximize the possible synergies among them. Examples of these possible synergies are represented by the combination of photovoltaic panels with heat pumps or refrigeration cycles and/or CHP internal combustion engines with absorption refrigeration cycles (tri-generation).

Both local and national institutions are growing an interest and taking initiatives in this field, hence research projects and investments arise, involving both private and public subjects. An example of this is the "Efficity" project - Efficient Energy Systems for Smart Urban Districts (www.efficity-project.it), cofunded by Emilia-Romagna Region (Italy), whose objective is the development of a software platform able to optimize the design, scheduling and control of smart energy networks - both conventional and renewables-based - serving urban districts, public and commercial buildings. Indeed, the first step towards

* Author to whom all correspondence should be addressed: e-mail: emanuele.martelli@polimi.it; Phone: +3902 23993908 
the aforementioned synergy maximization is the validation of its technical feasibility and economical profitability through mathematical optimization models, whose results could give important indications about which driving forces would play a major role - either positive or negative - in the development and diffusion of such systems.

When dealing with MES and DES design optimization, both centralized and distributed generation solutions should be taken into account; thus, a design optimization model has to accommodate for the possibility of installing multiple energy conversion units of variable size in many different locations of the district, making the problem extremely more difficult to solve than a single site problem. Moreover, in order to avoid operational issues and/or poor energy performances of the units, the optimal design has to take into account the partload performances and operational limitations (e.g., start-up/shut-down time and costs, ramp-up rates etc.) that characterize the operation of the energy conversion units (Yokoyama et al., 2002).

The characterization of the off-design performances of the units, together with the size effects on the nominal performances and costs, introduces many non-linearities, leading to challenging nonconvex Mixed Integer Nonlinear Program (MINLP) problems. To tackle such problems, two main approaches can be found in literature: the first one features a decomposition of the entire problem into a design and an operation subproblem, the second one entails the linearization of the nonlinear relations so as to convert the MINLP into a large-scale Mixed Integer Linear Program (MILP) problem.

A thorough literature review about the methods developed by various research groups following either approach can be found in (Elsido et al., 2017). On one hand, the MILP formulation introduces a larger approximation error in modelling the nonlinear partload performances and the size effects, but, on the other, tackling a MILP has the following advantages: i) there are global optimality guarantees, ii) the solution accuracy is constantly known and returned by the solver as the branch and bound gap, iii) extremely effective commercially MILP solvers are available, e.g. CPLEX (https://www.ibm.com/analytics/cplexoptimizer) and Gurobi (http://www.gurobi.com), which can successfully tackle large scale problems with thousands of binary variables. In light of these aspects, we have chosen the second approach. The MILP design optimization problem that we have developed has a two-stage structure: the design decisions (first stage) are taken in light of the optimal operation strategy (second stage).

In order to guarantee the computational tractability, the operation problem is solved for a limited set of typical periods (e.g., days or weeks), for which the hourly profiles of energy demands, energy prices and energy production from Renewable Energy Sources (RES) are usually considered. The selection of these typical periods has been widely studied in literature (Kotzur et al., 2018) and, in a previous work, we analyzed the impact of these selection techniques on the design (Zatti et al., 2018). In this work, a case study has been developed to assess the optimal retrofit for a district energy system represented by a University Campus in Northern Italy, which features electricity, heating and cooling demands. The MILP optimal design problem is solved with state-of-the-art MILP solvers. The impacts of different strategies as concerns the possibility of having energy load outages, $\mathrm{CO}_{2}$ taxation and tri-generation implementation have been assessed.

\section{Material and methods}

\subsection{Case study description}

Within the "Efficity" project, besides the development of the novel algorithms for the optimization of the design and the operation of MES, there is a great interest in assessing the potential of practical economic and environmental benefits from the spread of such systems. Thus, both research institutes and private companies have been involved. Thanks to this, we have the chance to test our algorithms on real data, made available by the partners of the project. In this work, we determine the retrofit design of energy supply system which minimize the total annual cost in a University Campus in Northern Italy, featuring electricity, heating and cooling demands. The University Campus features in total about 30 buildings spread over an area of approximately $0.77 \mathrm{~km}^{2}$. The fulfilment of the heating and cooling demands of buildings in the Campus of the University of Parma is provided by a district heating and cooling network.

The network is fed by five natural gas boilers and four compression refrigeration cycles located in the central site: the heating and cooling networks reach all the other buildings through four independent water loops, as shown in Fig. 1. The mass flow rate in each building heat exchanger is regulated by means of a bypass valve in order to maintain the temperature inside the building equal to $20{ }^{\circ} \mathrm{C}$ during working hours. The test case is relevant since it is representative of a medium scale district heating and cooling network which serves buildings with different sizes, envelope characteristics and destinations (offices, sport facilities, classrooms, etc.) in the tertiary sector. Moreover, the location in the north of Italy implies a quite high variability of external temperature during the heating period, and therefore sizing and management of the energy systems is of utmost importance.

The objective of this study is to determine the retrofit design of the energy supply system which minimizes the total annual cost (annualized capital costs + operating costs). We assume that all the existing units (boilers and refrigeration cycles) are to be replaced by new installations, whereas, in order to limit the capital cost of the retrofit, the layout of the heating and cooling networks are kept fixed. 


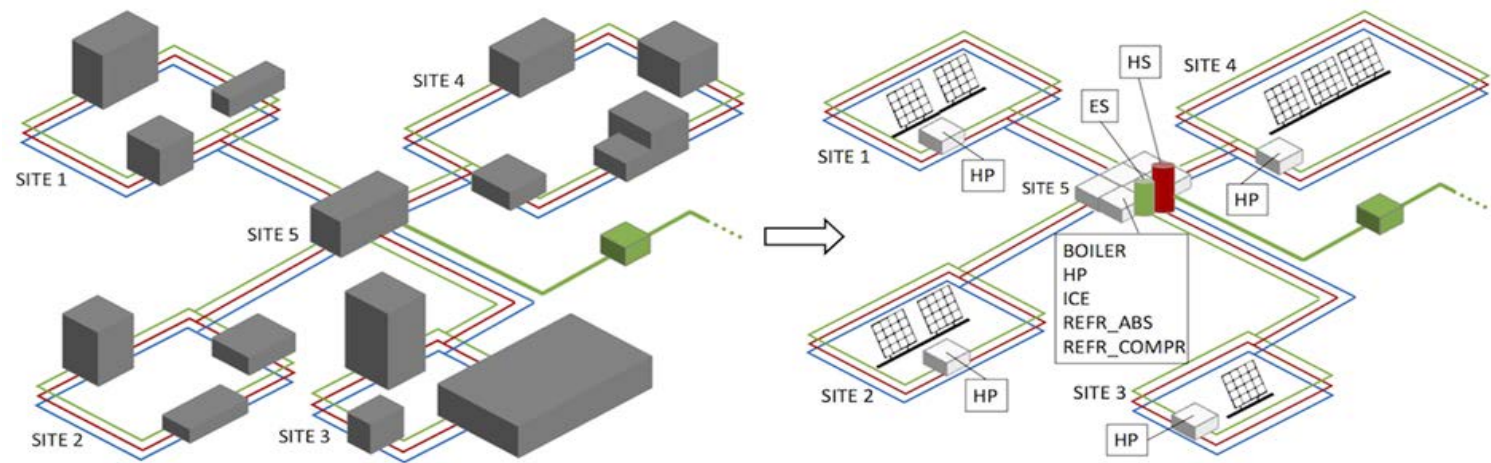

Fig. 1. From a generic district to the actual Campus: conceptual sketch. The algorithm is bounded to install each technology only in the pre-specified sites. Networks: blue $=$ cooling, red $=$ heating, green $=$ electricity. The district is connected to the national electricity grid (green box). $\mathrm{HP}=$ heat pumps, ICE = internal combustion engine, REFR_ABS = absorption refrigeration cycle, REFR_COMPR = compression refrigeration cycle, ES = electrical storage, HS = heat storage

One of the main advantages of using the approach proposed within the "Efficity" project is the ability to explore several configurations, trying to exploit possible synergies between different technologies to achieve the desired objective.

Thus, we give our algorithm the faculty to choose among several technologies: cogeneration internal combustion engines (ICE), natural gas boilers (BOILERS), compression refrigerators (REFR_CMPR), absorption refrigeration cycles (REFR_ABS), heat pumps (HP), photovoltaic (PV) panels and solar heating (SH) panels, heat storage (HS) tanks and electrical storage (ES), that is batteries. According to the site characteristics, it has been assumed that internal combustion engines, natural gas boilers and compression refrigerators can only be located in the central site. The number of machines that can be installed in each site and the surface available for the installation of PV and SH panels are also parameters of the model.

The heat produced by both heat pumps and solar heating panels can be used only in the site where they are installed: the heat is exchanged with the secondary loop in order to exploit its lower temperature (leading to a higher efficiency of the units) compared with the one of the primary loops. The algorithm has also the possibility to install heat storages in the central site. The presence of internal combustion engines, compression and absorption refrigeration cycles and heat pumps in the technology roster is very challenging, since they produce couplings between energy networks. If on one hand this set-up adds complexity to the system, on the other it allows for larger optimization, especially with respect to the current situation.

Hourly values for one year of heating, cooling and electricity demand have been used as input of the model. As concerns heating and cooling, data were made available for each building in the campus as results of both data collection and physical models, as described in (Gambarotta et al., 2017). As regards the electricity demand, only measures of the total monthly demands of the campus were available. They have been allocated to the different buildings considering that during evening hours, weekends and holidays the buildings are closed; thus, they feature very low and constant electricity demand. This assumption is confirmed by the characteristic daily and weekly profiles of schools, which can be found in the literature (RSE, 2009).

In addition to the energy demand profiles, hourly values for ambient temperature and solar irradiation have been retrieved and used for the identification of the typical and extreme days. Global horizontal irradiance and beam horizontal irradiance data have been used to calculate the global irradiance on a tilted surface (angle $=35^{\circ}$, commonly used value at these latitudes), assumed to be directed towards south, so as to maximize the daily and yearly production. Finally, hourly electricity prices have been collected from the Italian power exchange website. The one-year time series for the relevant attributes (normalized between 0 and 1 ) are reported in Fig. 2.

\subsection{Formulation of the optimization model}

The design optimization problem considered in this work has been formulated as a two-stage MILP problem, involving investment decisions (first stage) and operation decisions (second stage). This two-stage structure is represented by the following compact formulation, Eqs. (1 - 5):

$$
\begin{aligned}
& \min T A C=\sum_{u \in U} C^{I N V} \cdot x_{u}^{(1)}+\sum_{t \in T} C^{O P} \cdot x_{u, t}^{(2)} \\
& x_{u}^{(1)} x_{u, t}^{(2)}
\end{aligned}
$$

Subject to:

$$
\begin{aligned}
& A^{(1)} x_{u}^{(1)}+A^{(1)} y_{u}^{(1)}=b_{u}^{1} \\
& A^{(2)} x_{u}^{(2)}+A^{(2)} y_{u}^{(2)}=b_{u}^{2}
\end{aligned}
$$




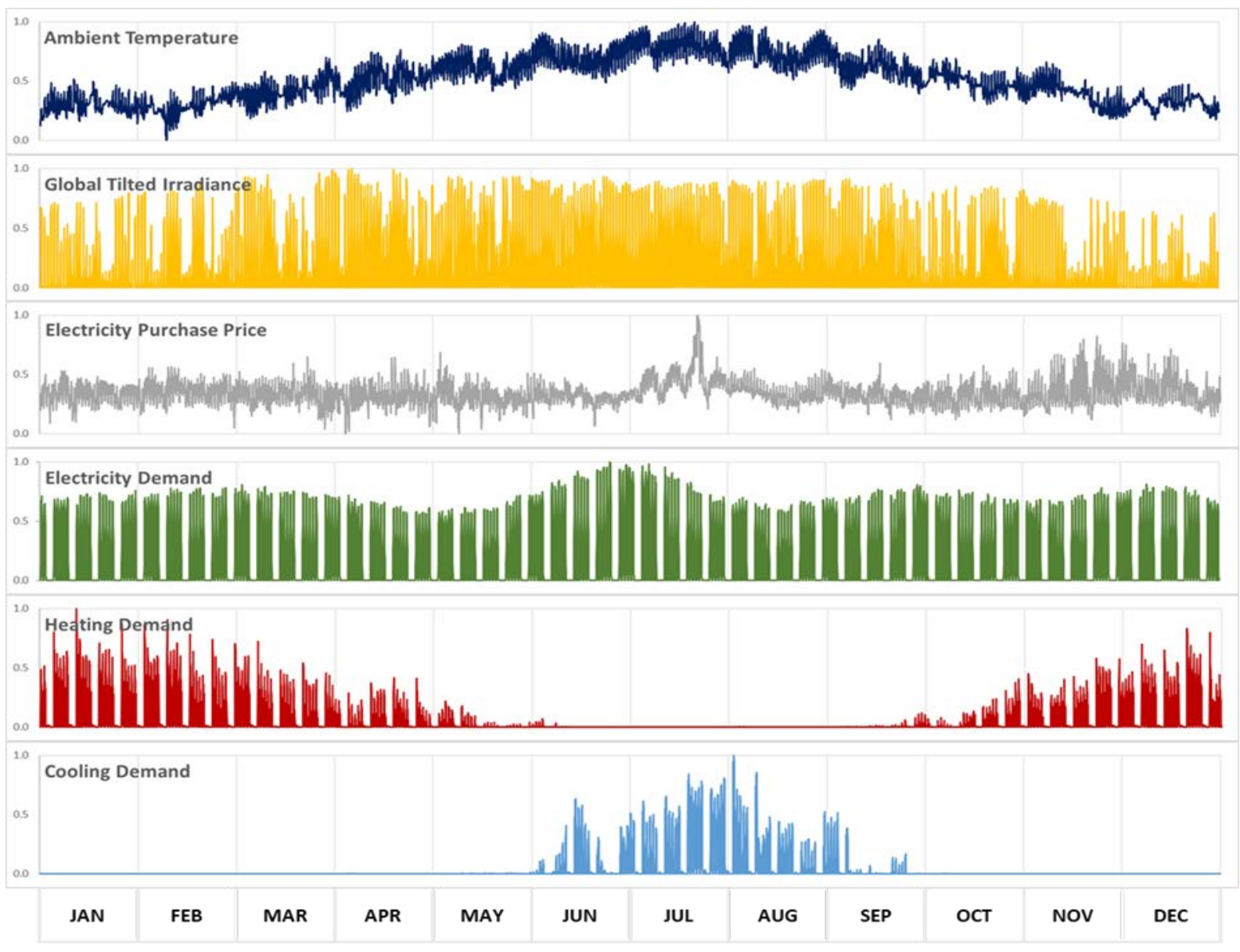

Fig. 2. One-year original data set of heating, cooling and electricity demands (the profiles report the total of the five sites), electricity purchase price, ambient temperature and the irradiance on a tilted surface $\left(35^{\circ}\right)$ oriented towards south

$A^{(1)} x_{u}^{(1)}+A^{(1)} y_{u}^{(1)}+A^{(2)} x_{u, t}^{(2)}+A^{(2)} y_{u, t}^{(2)}=b_{u, t}^{(1,2)}$

$x_{u}^{(1)} \in R, \quad x_{u, t}^{(2)} \in R, \quad y_{u}^{(1)} \in\{0,1\} \quad y_{u, t}^{(2)} \in\{0,1\}$

where $T A C=C A P E X+O P E X$ is the total annualized costs; $u \in U$ is the sets of energy conversion and storage units and $t \in T$ is the set of time steps considered in the operation. $x^{(1)}$ and $y^{(1)}$ are, respectively, the continuous (unit sizes, storage capacities, network branches capacities) and binary (unit/storage/network branch selection and installation) investment variables, and $x^{(2)}$ and $y^{(2)}$ are the continuous (unit load, storage level, network branch power flow) and binary (unit on/off status) operation variables.

As seen from Eq. (5), there are real and binary variables in both stages making the problem structurally similar to a two-stage stochastic problem with integer recourse (Birge and Louveaux, 2011). There are constraints that accounts only for the investment stage, as in Eq. (2), e.g. the minimum and maximum unit sizes or the available locations for the installation of the units. There are also constraints referring only to the operation stage, as in Eq. (3), e.g. the balances between the energy production and demand. Finally, as in Eq. (4), there are constraints that bind the first and the second stage variables, e.g. the performance maps of the units which depend on their size. This model presents many similarities with the methods described in (Bracco et al., 2016; Buoro et al., 2014; Gabrielli et al., 2018; Yang et al., 2015; Yokoyama et al., 2002; Yokoyama and Ito, 2006), which linearize the part-load performances of the units. Yet, our model is characterized by the simultaneous presence of three elements, which is not the case for the aforementioned works: i) a multisite structure, ii) the capacities of the units to be chosen by the algorithm are continuous variables for all the possible technologies and the size effects on performances are linearized with the approach proposed by Yokoyama et al. (2002), iii) the part load behavior of the units is modelled using the convex hull formulation (Lahdelma and Hakonen, 2003). These characteristics make it more general.

The problem is solved assuming that the energy production system serving the Campus nowadays is at the end of its life and the new energy conversion and storage units chosen by the design optimization model, once installed, have to work for the following 20 years, without any replacement or further intervention, except for the ordinary maintenance. The TAC are computed with respect to such time horizon, assuming an interest rate equal to 0.08 . The district 
energy system is connected to the national gas and eletric grids, with the possibility of withdrawing or injecting electrical energy whenever it prefers. Finally, the charge/discharge cycle of the thermal storage is considered to be of 24 hours, that is the level of water in the hot water tank at the beginning and the end of the day has to be the same.

\subsection{Modelling and performance linearization of energy technologies}

We have modelled the performance and the costs of the aforementioned energy technologies by using: Thermoflex (Thermoflow ${ }^{\circledR}$ ) for internal combustion engines and data derived from commercially available catalogues for heat pumps (Gabrielli et al., 2017) and for refrigeration cycles. Moreover, we have used the approaches available in SDH (2012) and Skoplaki and Palyvos (2009) for solar thermal and PV panels), respectively, together with data found in commercially available catalogues. Finally, concerning hot water heat storage systems we have used the approach proposed in Barbaro (2009) and data available in Turton et al. (2008). Such models account for: 1) economies of scale on capital costs 2) nonlinear size effects on nominal performances and 3) part-load operation of the units.

To be able to model within a MILP problem the performance of the energy technologies, we have linearized all the size effects on costs and efficiency of generation units. As for the performance at part loads and size effects, the correlation between the output (i.e. thermal, electrical or cooling power) and the input of the machine (i.e. fuel, electric or thermal power) has been linearized following the approach described by Yokoyama et al., (2002) and the convex hull formulation described in (Lahdelma and Hakonen, 2003), which results in the following formulation, Eqs. $(6-11)$ :

$$
\begin{aligned}
& p_{u, t}=k^{1 P} \cdot i n_{u, t}+k^{2 P} \cdot S_{u}+k^{3 P} \\
& q_{u, t}=k^{1 Q} \cdot i n_{u, t}+k^{2 Q} \cdot S_{u}+k^{3 Q} \\
& r_{u, t}=k^{1 R} \cdot i n_{u, t}+k^{2 R} \cdot S_{u}+k^{3 R} \\
& k_{M I N}^{I N} \cdot S_{u} \leq i n_{u, t} \leq k_{M A X}^{I N} \cdot S_{u} \\
& i n_{u, t}=\sum_{v=1}^{N v} \alpha_{u, v, t} \cdot k_{v}^{I N} \cdot S_{u} \\
& \sum_{v=1}^{N v} \alpha_{u, v, t}=z_{u, t}
\end{aligned}
$$

where: $p_{u, t}, q_{u, t}$ and $r_{u, t}$ are, respectively, the electrical, thermal and cooling output of machine $u$ at time $t$. $i n_{u, t}$ is the input of the unit, which is: 1) fuel for boilers and ICEs, 2) electricity for heat pumps and compression refrigeration units and 3) thermal power for absorption refrigeration units. $S_{u}$ is the size of the unit. $\alpha_{u, v, t}$ is the variable used for the convex hull formulation (where $v$ are the vertexes) and $z_{u, t}$ is the binary on/off variable. Thanks to Eq. (11), the product of the two variables in Eq. (10) can be linearized.

The $k^{1 P}, k^{2 P}$ and $k^{3 P}$ coefficients are used to linearize the size effect and the part load performances of the electrical output in Eq. (6), and similarly for thermal output in Eq. (7) and cooling output in Eq. (8). Eq. (9) is meant to set the minimum and maximum load of a unit, as a function of its size.

As an example of the methodology used to calculate the set of coefficients, we illustrate here the results concerning the internal combustion engine performance linearization; the other technologies follow similar patterns. We have collected - from catalogues and Thermoflex - thermal and electric efficiencies, both for on- and off-design conditions, for engines between $1500 \mathrm{~kW}_{\mathrm{e}}$ and $18000 \mathrm{~kW}_{\mathrm{e}}$ of electric power output. On the basis of these data, engines can be classified into two families, as shown in Fig. 3: "small" engines, with efficiency depending on the nominal electric power output, and "large" engines, for which the efficiency is independent from the nominal electric power output.

We have evaluated the set of coefficients required in Eqs. $(6-10)$ for both engine families. To do so, we have selected a single producer with engine covering the whole "small" size range. The fitting of the available data results in the coefficient sets in Table 1, suitable for modeling all the range of "small" engines as shown in Fig. 4a, Fig. 4b and Fig. 4c. A similar fitting procedure has been carried out to linearize the off-design thermal power output map for the same engines.

Similarly, we have calculated the linearization coefficients for the other technologies included in our model. Coefficient values are reported in Table 1. As it can be seen in Fig. 4d and Fig. 4e, in order to model the part-load performances of the compression refrigeration units, it is better to use a piece-wise formulation entailing two segments; thus, two sets of coefficients are required.

As for the operational limits of the units, in the model we have enforced minimum up-time constraints in order to avoid abrupt turn-on and shut-down of the machines during the day, which would drastically diminish the life time of the units.

Costs are evaluated based on data available from commercial catalogues using the function reported in Eq. (12).

$C_{u}=C_{u, 0} \cdot\left(\frac{S_{u}}{S_{u, o}}\right)^{f u}$

where $C_{u}$ is the total investment cost of unit $u$ of size $S_{u} \cdot C_{u, 0}$ is the total investment cost of unit $u$ at the reference size and $f_{u}$ is the proper scale factor.

We linearize these costs using piecewise functions featuring three segments; the breakpoints for each technology are reported in Table 2, together with the specific costs we have assumed for heat storage tanks (Euro $/ \mathrm{m}^{3}$ ) and solar heating panels (Euro $/ \mathrm{m}^{2}$ ). 


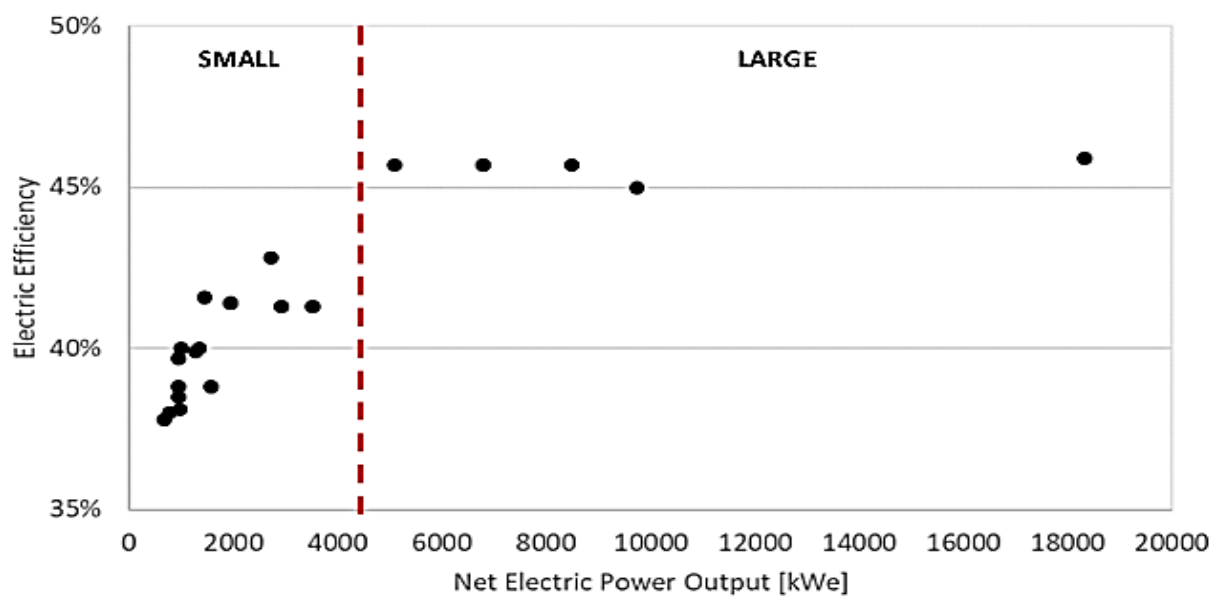

Fig. 3. Classification of engines based on the correlation between electric efficiency and net electric power output

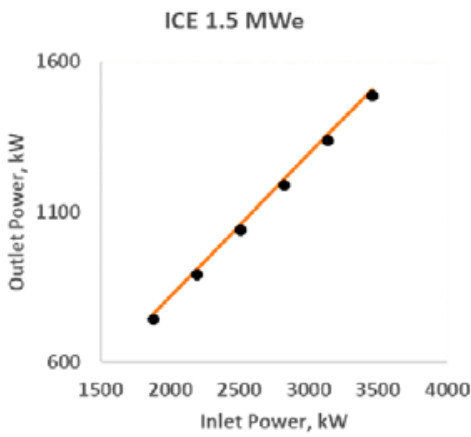

(a)

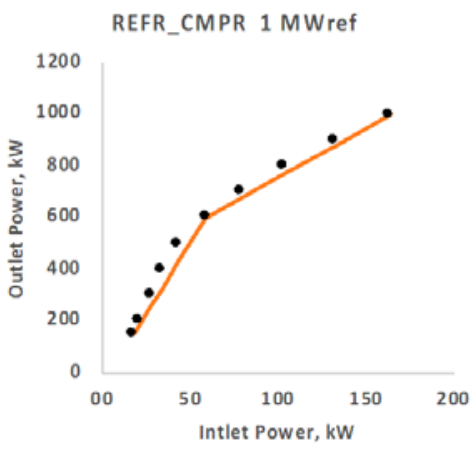

(d)

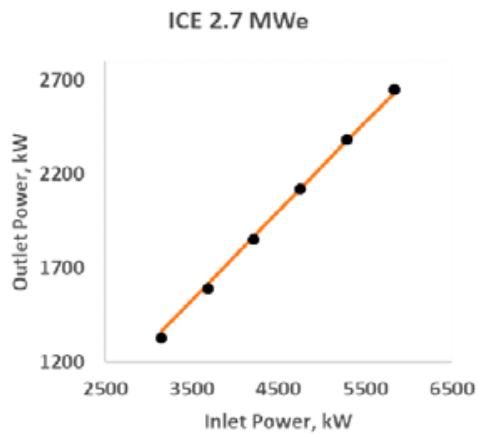

(b)

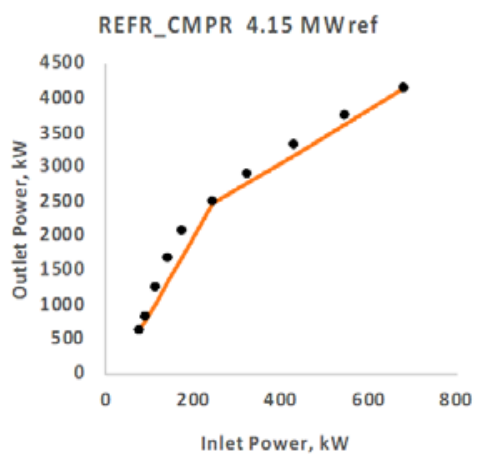

(e)

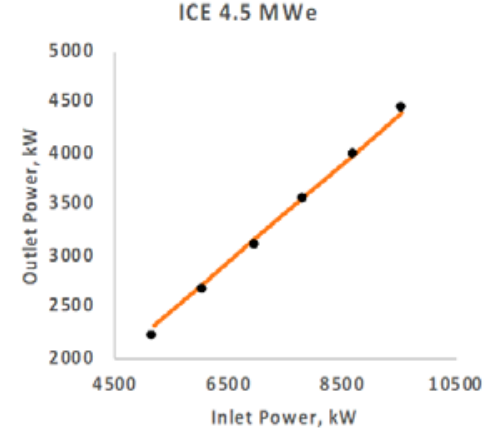

(c)

Fig. 4. Piecewise linearization of the performances of the internal combustion engines (ICE) and the compression refrigeration cycles (REFR_CMPR): (a), (b), (c) are three relevant sizes for the ICEs in the "small” range and (d),

(e) are two relevant sizes for the REFR_CMPRs

Table 1. Linearization coefficients sets for the technologies considered in the case study (ICE = internal combustion engine; REF_CMPR = compression refrigeration cycle, REF_ABS = absorption refrigeration cycle, HP = heat pump)

\begin{tabular}{|c|c|c|c|c|c|c|c|c|c|}
\hline \multirow{2}{*}{ UNIT TYPE } & \multicolumn{3}{|c|}{ Electricity Output } & \multicolumn{3}{c|}{ Thermal Output } & \multicolumn{3}{c|}{ Cooling Output } \\
\cline { 2 - 9 } & $\boldsymbol{k}^{\mathbf{P}}$ & $\boldsymbol{k}^{\mathbf{P}}$ & $\boldsymbol{k}^{\mathbf{3 P}}$ & $\boldsymbol{k}^{\mathbf{Q}}$ & $\boldsymbol{k}^{\mathbf{Q}}$ & $\boldsymbol{k}^{\mathbf{3 Q}}$ & $\boldsymbol{k}^{\mathbf{1 R}}$ & $\boldsymbol{k}^{\mathbf{2 R}}$ & $\boldsymbol{k}^{\mathbf{3 R}}$ \\
\hline HP & & & & 3.590 & -0.080 & 0.000 & & & \\
\hline BOILER & & & & 0.976 & -0.032 & 4.338 & & & \\
\hline "SMALL" ICE & 0.490 & -0.017 & -128.830 & 0.439 & -0.005 & 108.180 & & & \\
\hline "LARGE" ICE & 0.507 & -0.043 & 0.000 & 0.429 & 0.015 & 0.000 & & & \\
\hline REF_CMPR (1st Segment) & & & & & & & 11.103 & -0.324 & 0.000 \\
\hline REF_CMPR (2nd segment) & & & & & & & 3.806 & 2.295 & 0.000 \\
\hline REF_ABS & & & & & & & 0.781 & 0.000 & 0.000 \\
\hline
\end{tabular}


Table 2. Cost evaluation: breakpoints for piecewise linearization and specific costs. The size is expressed in terms of the input as indicated in unit type, the cost is expressed in kEuro; the specific cost is expressed in Euro and is specific to the unit of measure of the unit type (HP = heat pump, ICE = internal combustion engine, REF_CMPR = compression refrigeration cycle, REF_ABS = absorption refrigeration cycle, $\mathrm{SH}=$ solar heating, $\mathrm{HS}=$ heat storage, $\mathrm{ES}=$ electrical storage)

\begin{tabular}{|c|c|c|c|c|c|c|c|c|c|}
\hline \multirow{2}{*}{ UNIT TYPE } & \multicolumn{4}{|c|}{$S I Z E$} & \multicolumn{4}{|c|}{ COST [kEuro] } & \multirow{2}{*}{ SPECIFIC COST } \\
\hline & 1 & 2 & 3 & 4 & 1 & 2 & 3 & 4 & \\
\hline HP, kWel & 100 & 500 & 2000 & 10000 & 254 & 778 & 2039 & 6239 & \\
\hline BOILER, kW fuel & 100 & 1000 & 10000 & 50000 & 8 & 69 & 554 & 2387 & \\
\hline ICE, $\mathbf{k W}$ fuel & 1328 & 13783 & 26237 & 38692 & 247 & 2296 & 4242 & 6145 & \\
\hline REF_CMPR, kWel & 165 & 337 & 508 & 680 & 248 & 428 & 587 & 733 & \\
\hline REF_ABS, kW $\mathbf{W}_{\text {th }}$ & 192 & 2348 & 4505 & 6661 & 136 & 385 & 505 & 594 & \\
\hline HS, $\mathbf{m}^{3}$ & 1 & 2000 & 5000 & 10000 & 5 & 626 & 1131 & 1770 & \\
\hline ES, kWh & & & & & & & & & 500 \\
\hline $\mathrm{SH}, \mathrm{m}^{2}$ & & & & & & & & & 350 \\
\hline
\end{tabular}

\subsection{Selection of typical and extreme days}

Since optimizing the operation in the whole set of time steps (e.g., 8760 hours to evaluate the total annual cost) would make the problem computationally intractable, due to the large number of binary on/off variables, time series aggregation must be used to find a few representative operating profiles (Fazlollahi et al., 2014) or to group the binary operational variables (Gabrielli et al., 2017) and reduce the problem size. The required feature of such aggregation is to be representative of the original time series, in such a way that: 1) the operational feasibility is preserved and 2) the operational costs appearing in the objective function resemble properly the actual operational costs. For the first task, extreme periods are usually added to the input data set, while for the second one, clustering techniques are commonly used.

As thoroughly explained in (Kotzur et al., 2018), the aim of time series aggregation techniques is to gather a set of periods $i \in\left\{1, \ldots, N_{i}\right\}$ (e.g. the 365 days of a year), each consisting of the same number of time steps $h \in\left\{1, \ldots, N_{h}\right\}$ (e.g. the 24 hours), with $N_{a}$ attributes (e.g. heating demand, irradiance, etc.), into a pre-defined $N_{k}$ number of groups such that the group members are as similar as possible.

Usually, the aggregation is performed by minimizing a distance measure of the attributes between each group member. The groups are then represented by a single period. The selection of the representative period, often called typical periods, depends on the specific techniques. Moreover, since the typical periods are the most representative profiles of the clusters, extreme periods are not included and need to be added so as to enforce the operational feasibility of the system throughout the year.

In this work, the attributes considered for the clustering are: the heating, electricity and cooling demands, the irradiance, the ambient temperature and the electricity prices.

Moreover, based on the periodicity of the energy demand profiles, of the physical phenomena (sun irradiance) and the typical usage of the storage systems, the time step basis we have chosen for the typical periods is 24 hours, that is we have considered typical days.
In order to determine typical and extreme days, the systematic MILP-based clustering method proposed in Zatti et al. (2018) has been used. It is an improvement of the k-medoids clustering approach in which: 1) it is possible to bound the maximum violation of the total yearly value of each attribute (e.g., the sequence of selected typical days and actual days must have similar total yearly electricity/heat/cooling demand), 2) the most atypical days are automatically identified as "extreme days" see further details in Zatti et al. (2018).

To preserve computational tractability of the optimization problem, 6 typical and 6 extreme days have been considered to represent the whole operating year. Their normalized profiles are reported in Fig. 5 (values have been normalized between the minimum and maximum value reached by each profile).

\subsection{Investigated scenarios}

The MILP design optimization model has been applied to the case study considering 6 different scenarios:

- $\quad$ Scenario 1: outages are not allowed (the heat and cooling demand must always be satisfied by the installed units).

- $\quad$ Scenario 2: if the energy systems supplying heat and cooling power cannot meet the users' demands in a certain hour of the day, a fixed fee of 5000 Euro/hour must be paid plus a fee proportional to the load shedding (100 and 200 Euro per MWh of, respectively, heating and cooling demand not met).

- $\quad$ Scenario 3: in case of outages, only a variable fee of 100 and 200 Euro per MWh of, respectively, heating and cooling demand not met is paid.

- $\quad$ Scenario 4: same assumptions as Scenario 2 with the addition of a $\mathrm{CO}_{2}$ emissions tax equal to 100 Euro/tCO $\mathrm{CO}_{2}$. In this scenario, cogeneration and renewable technologies should be favored compared to the use of natural gas boilers.

Scenario 5: same techno-economic assumptions as scenario 4 but with the additional possibility of installing an absorption refrigeration unit in site 5 




(a)

Extreme days

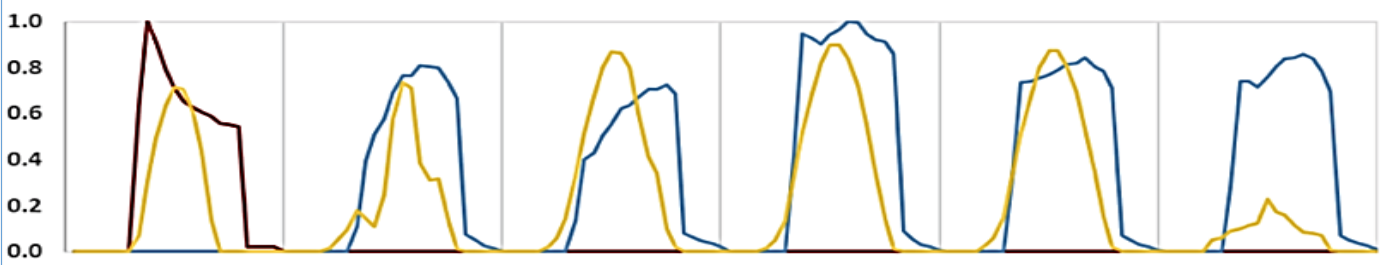

(b)

Fig. 5. Normalized profiles for heating demand (red curve), cooling demand (light blue curve) and irradiance (yellow curve) of: (a) the 6 typical days and (b) the 6 extreme days

- $\quad$ Scenario 6: same assumptions as scenario 5 but with the possibility to use the thermal power produced by the solar heating in the whole districts through the primary heat distribution network; this lowers the average yearly efficiency of the SH panels because of the higher temperature of the water to be heated up $\left(95^{\circ} \mathrm{C}\right)$ compared to the secondary internal building loops $\left(45-60^{\circ} \mathrm{C}\right)$.

For all the above-listed scenarios, a natural gas price of 0.039 Euro/kWh $\mathrm{LHV}_{\mathrm{LH}}$ has been assumed.

\section{Results}

\subsection{Design results}

Table 3 and Table 4 report the design optimization results in terms of selection of installed units and annualized costs respectively. As it can be seen, in scenario 1 , the optimal design must feature 3 boilers (a large one covering approximately $56 \%$ of the peak heating demand and two much smaller ones), a large ICE covering between $58 \%$ of the peak electricity demand, 3 refrigeration cycles (two large ones covering $45-50 \%$ of the demand and a smaller one) and a heat storage system (100 $\mathrm{m}^{3}$ volume) to be installed in site 5, plus a heat pump to be installed in site 1 . The peak demand of heating is met by using all the boilers, the ICE and discharging the heat storage system. Thanks to the thermodynamic advantage of the cogeneration engine, the optimized management of the storage system and the optimized layout and sizing, the retrofit solution generates $21 \%$ less $\mathrm{CO}_{2}$ emissions than the current design. This result is remarkable considering that no $\mathrm{CO}_{2}$ emission taxes or incentives for renewable energy technologies is considered. In scenarios 2 and 3, the optimal design exploits the possibility of making outages to save some capital costs and, thus, it reduces the capacity of installed boilers. In scenario 2, the designed system is not able to meet $0.85 \%$ of the requested heat demand while in scenarios 3 , due to the lower outage fees, this fraction rises to $2.5 \%$. Similarly, to scenario 1 , also in scenarios 2 and 3 the optimal solution essentially resembles the centralized paradigm to exploit economies of scale. Even if in scenario 3 outages are allowed and not expensive, renewable technologies (solar PV and solar thermal panels) are not exploited because of their higher costs compared to conventional fossil-fired technologies (boilers and ICEs).

It is worth noting that the actual TAC of scenario 2 (TAC assessed by optimizing the operation day-by-day for the whole year) is worse than that of scenario 1, even though scenario 2 features a relaxation of the constraints of scenario 1 (i.e., it should feature a TAC equal or lower than scenario 1 ). This is due to the approximation caused by the typical periods which, within the design optimization problem, underestimate the number of outage hours compared to the actual operating profiles.

In Scenario 4, the capacity of the boilers is decreased and that of the CHP ICE is increased so as to lower the $\mathrm{CO}_{2}$ emissions thanks to the fuel saving effect of cogeneration. When possible, peaks of heat demand are met by discharging the heat storage system. On average, $0.82 \%$ of the heat demand is not met across the whole year (i.e. during the peak demand hours, occurring only a few hours per year). Cooling power is provided by refrigeration cycles, which are sized to meet the peak demand. Given the assumed $\mathrm{CO}_{2}$ emissions tax, solar PV panels are not installed because less cost-effective than CHP ICEs (the installed ICE cogenerates useful heat in addition to the electricity). 
Table 3. Selection of the units (S1.S5 is the site number; SH = Solar Heating; HP = Heat Pump; ICE EL = electricity produced by Internal Combustion Engine; ICE TH = Heat produced by Internal Combustion Engine; REF_CMPR = compression refrigeration cycle, REF_ABS = absorption refrigeration cycle, HS = Heat Storage)

\begin{tabular}{|c|c|c|c|c|c|c|c|c|c|c|c|c|c|c|c|c|}
\hline \multirow{3}{*}{$\begin{array}{c}\text { SCENARIO } \\
1 \\
\end{array}$} & \multirow{2}{*}{$\begin{array}{c}S 1 \\
S H \\
{\left[m^{2}\right]}\end{array}$} & \multicolumn{2}{|c|}{$S 2$} & \multicolumn{13}{|c|}{ S5 } \\
\hline & & \multirow{2}{*}{\begin{tabular}{|c|} 
HP \\
0.147 \\
\end{tabular}} & \multirow[t]{2}{*}{$\begin{array}{c}S H \\
{\left[m^{2}\right]} \\
\end{array}$} & \multicolumn{3}{|c|}{ BOILERS } & \multicolumn{2}{|c|}{$\begin{array}{c}\text { ICEs } \\
\text { EL }\end{array}$} & \multicolumn{2}{|c|}{$\begin{array}{c}\text { ICEs } \\
\text { TH }\end{array}$} & \multicolumn{3}{|c|}{ REF_CMPRs } & \multicolumn{2}{|c|}{$R E F \_A B S s$} & \multirow{2}{*}{\begin{tabular}{|c|}
$\begin{array}{c}\boldsymbol{H S} \\
{\left[\mathbf{m}^{3}\right]}\end{array}$ \\
100
\end{tabular}} \\
\hline & & & & 0.564 & 0.023 & 0.006 & 0.585 & & 0.158 & & 0.502 & 0.456 & 0.167 & & n.a. & \\
\hline 2 & & 0.132 & 9 & 0.248 & 0.023 & 0.007 & 0.603 & & 0.163 & & 0.484 & 0.474 & 0.167 & & n.a. & 100 \\
\hline 3 & & 0.131 & & 0.181 & 0.004 & 0.004 & 0.602 & & 0.163 & & 0.450 & 0.122 & & & n.a. & 100 \\
\hline 4 & & 0.139 & 9 & 0.236 & 0.004 & 0.004 & 0.754 & & 0.205 & & 0.496 & 0.461 & 0.167 & & n.a. & 77 \\
\hline 5 & 265 & 0.132 & 2 & 0.228 & & & 0.684 & 0.081 & 0.185 & 0.022 & 0.131 & & & 0.586 & 0.297 & 100 \\
\hline 6 & & 0.147 & 441 & 0.266 & 0.005 & & 0.701 & & 0.190 & & 0.328 & 0.122 & & 0.586 & & 100 \\
\hline
\end{tabular}

Table 4. Annualized costs, heating and cooling demand outages, fossil $\mathrm{CO}_{2}$ emissions for the six scenarios. Capex: Capital expenditures, Opex: operation expenditures, TDs: typical days, TAC: Total Annualized Costs = Capex + Opex. All the economic values have been normalized with respect to the TAC calculated considering TDs of the first scenario. The outages are reported as fraction of the corresponding total energy demands

\begin{tabular}{|l|c|c|c|c|c|c|c|c|}
\hline & \multicolumn{3}{|c|}{ COSTS } & \multicolumn{2}{c|}{ OUTAGES } & \multirow{2}{*}{$\begin{array}{c}\text { FOSSIL CO } \\
\text { EMISSIONS }\end{array}$} \\
\hline SCENARIO & $\begin{array}{c}\text { Annualized } \\
\text { Capex }\end{array}$ & Opex TDs & $\begin{array}{c}\text { Opex 365 } \\
\text { days }\end{array}$ & TAC TDs & $\begin{array}{c}\text { TAC 365 } \\
\text { days }\end{array}$ & heating & cooling & EMIO \\
\hline $\mathbf{1}$ & 0.30 & 0.70 & 0.69 & 1.00 & 0.98 & $0.00 \%$ & $0.00 \%$ & 0.79 \\
\hline $\mathbf{2}$ & 0.27 & 0.71 & 0.77 & 0.98 & 1.04 & $0.85 \%$ & $0.00 \%$ & 0.78 \\
\hline $\mathbf{3}$ & 0.22 & 0.72 & 0.71 & 0.94 & 0.94 & $2.48 \%$ & $8.65 \%$ & 0.78 \\
\hline $\mathbf{4}$ & 0.29 & 1.06 & 1.12 & 1.35 & 1.41 & $0.82 \%$ & $0.00 \%$ & 0.77 \\
\hline $\mathbf{5}$ & 0.28 & 1.06 & 1.14 & 1.34 & 1.41 & $0.86 \%$ & $0.00 \%$ & 0.78 \\
\hline $\mathbf{6}$ & 0.28 & 1.05 & 1.09 & 1.33 & 1.38 & $0.52 \%$ & $0.00 \%$ & 0.77 \\
\hline
\end{tabular}

Likely, solar PV panels would be installed if higher $\mathrm{CO}_{2}$ emission taxes would be assumed. Although the assumed taxes on $\mathrm{CO}_{2}$ emissions cause a total annual cost increase by $40 \%$ compared to scenario 1 , the yearly total $\mathrm{CO}_{2}$ emissions are only $2 \%$ lower.

In scenario 5, the optimal solution features two absorption chillers (of different capacity) which, during summer, convert the heat produced by two CHP ICEs into cooling power. The absorption chiller allows using the CHP ICE also during summer with a slight capital cost saving compared to the installation of refrigeration cycles (Table 4). Thermal power for heating purposes is generated by a boiler and two CHP ICE placed in the central site (site 5), and a heat pump placed in site 2. A considerable extent of solar thermal panels is placed on the buildings of site 1 to contribute to the heat generation system (saving $\mathrm{CO}_{2}$ emissions). Compared to the previous ones, this scenario features a higher share of renewable sources and a more decentralized energy production system.

In Scenario 6, solar thermal panels can be installed to provide heat to the primary heat distribution system. Thus, their thermal power can be transferred from one site to the others via the existing heating network and, when necessary, converted into cooling power by the absorption chiller. This solution allows to use solar heating to contribute to the heat required by the absorption chiller, thus considerably increasing the utilization factor of the panels. As a result, the optimal design features $441 \mathrm{~m}^{2}$ of thermal solar panels in site 2 . On the other hand, due to the intermittency of solar radiation, only one absorption chiller is installed and it is capable of covering only half of the cooling demand. The remaining cooling power is provided by two refrigeration cycles, which guarantee operation also during cloudy days. For the assumed cost of $\mathrm{CO}_{2}$ emissions tax, Scenario 6 turns out to be less expensive (i.e., leading a $3 \%$ lower total annual cost) and less carbon intensive $(-1.5 \%$ total yearly $\mathrm{CO}_{2}$ emissions) than scenario 5 thanks to the lower operating costs.

\subsection{Operation results}

Fig. 6 shows the optimized operation of the installed units for the design solution of scenario 6 in a typical winter day (Fig. 6a) and a typical summer day (Fig. 6b). In the typical winter day, the integration of the ICE and the larger boiler together with an appropriate discharge of the thermal storage allows to cover the total heating demand of the district. In order to meet the minimum up time constraint, the ICE is used to charge the thermal storage in the evening so as to use the stored heat in the morning peak hours, together with the boiler. In the typical summer day, the ICE and the thermal storage are synergistically used to produce the heat required by the absorption chiller to match the cooling demand of the district. In the morning hours, the ICE is used to charge the thermal storage so that the latter can be used in the evening, when the district cooling demand reaches the peak values. Thanks to this strategy, the system can also benefit from the higher morning electricity sale prices. 


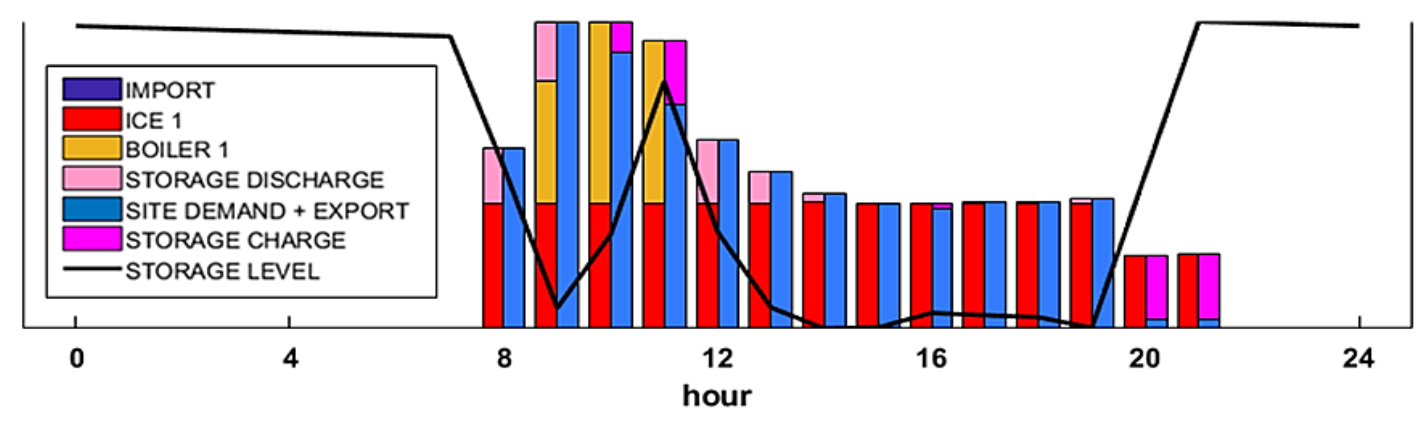

(a)

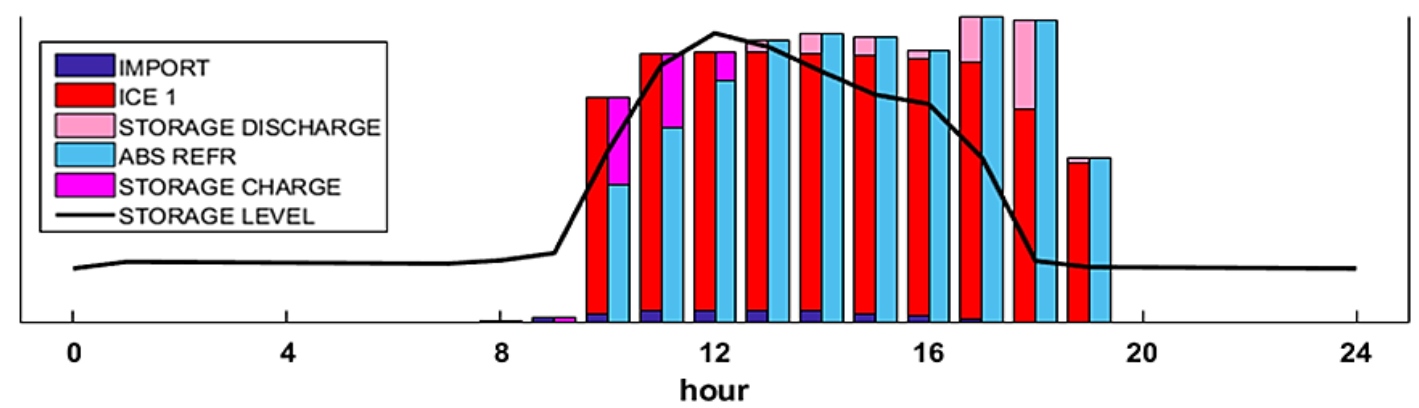

(b)

Fig. 6. Optimized operation of the installed units for the design of scenario 6. The plot reports the heat generated by the units installed in the central site of the campus (site 5) at each hour of the day, during: (a) a winter typical day and (b) a summer typical day. The left-hand bars show the positive contributions to the heat balance, that is the heat produced by the units, the heat storage discharge and the import from the solar panels located in site 2. The right-hand bars show the negative contributions to the heat balance, that is the site demand (please notice that the heating demand of site 5 is very low), the heat storage charge, the heat absorbed by the absorption chiller and the heat exported to the other sites of the campus. The bars are normalized with respect to the peak values reached within the day

\section{Conclusions}

The paper presents the systematic design methodology for multi-energy systems and smart energy districts developed in the framework of the "Efficity" project. The optimal design problem of multi-energy systems (MES) serving districts of buildings is formulated as a multi-period multi-site Mixed Integer Linear Program. The model includes accurate linearized cost and performance models of conventional and renewable energy technologies as well as energy storage systems. The approach has been applied to identify the best retrofit design for the energy system serving the Campus of University of Parma. Six interesting scenarios were considered featuring different costs of outages, $\mathrm{CO}_{2}$ emission taxes and retrofit options. For the scenarios without $\mathrm{CO}_{2}$ emission taxes (or incentives), the minimum cost solution essentially resembles a centralized paradigm with three boilers and a CHP ICE producing most of the required thermal power. Peak demands of heat are satisfied with the aid of a hot water storage tank. Renewable technologies are not selected because of their high specific capital costs (being no incentives). The optimal size of the required boilers depends on the fee to be paid for the heating outages. Even though
$\mathrm{CO}_{2}$ emission taxes are not considered, the retrofit design allows saving from about 21 to $22 \%$ of $\mathrm{CO}_{2}$ emissions compared to the current design, thanks to the fuel saving advantage of CHP engines and the optimized layout.

If $\mathrm{CO}_{2}$ emission taxes equal to 100 Euro/t are considered, the optimal solution from an economic and $\mathrm{CO}_{2}$ emissions point of view is the one of scenario 6 which includes two boilers, an internal combustion engine, an absorption chiller, two refrigeration cycles and a hot water tank in the central site (S5), plus a heat pump and more than $400 \mathrm{~m}^{2}$ of solar thermal panels in site 2. Solar thermal panels generate hot water for the primary distribution networks between sites which can be used during winter/spring/autumn for space heating and domestic hot water, and during summer to generate cooling power with the absorption cycle of site 5. Thus, the optimal solution calls for two-way heat flows between the sites, like in decentralized multi energy systems. Due to the assumed taxes on fossil $\mathrm{CO}_{2}$ emissions, the total annual cost rises by about $40 \%$ compared to the scenario without emissions penalties. On the other hand, the optimized design of scenario 6 allows saving only $2 \%$ more fossil $\mathrm{CO}_{2}$ emissions compared to scenario 1 (which is already quite efficient in reducing $\mathrm{CO}_{2}$ emissions 
thanks to the fuel savings effect of the CHP engine). In order to achieve higher $\mathrm{CO}_{2}$ emission savings, higher $\mathrm{CO}_{2}$ emission taxes (or incentives for solar PV or solar heating panels) should be set, but this would lead to a considerable penalty on the total annual cost.

An interesting result is that in all the considered scenarios solar PV panels are not selected to generate electric power because of their relatively higher investment costs (without incentives) compared to CHP engines (which have also the advantage of cogenerating useful heat).

\section{Acknowledgments}

The authors acknowledge SIRAM for the useful technoeconomic information and the key data of the case study. This work was supported by the "Efficity - Efficient energy systems for smart urban districts" project (CUP E38I16000130007) co-funded by Regione Emilia-Romagna through the European Regional Development Fund 20142020 .

\section{References}

Barbaro C., (2009), Optimization of poligeneration units and energy $\mu$-grids for applications in the residential sector (in Italian), PhD Thesis, Università degli Studi di Palermo, Palermo, Italy.

Birge J.R., Louveaux F., (2011), Introduction to Stochastic Programming, 2nd Edition, Springer, New York.

Bracco S., Dentici G., Siri S., (2016), DESOD : A mathematical programming tool to optimally design a distributed energy system, Energy, 100, 298-309.

Buoro D., Pinamonti P., Reini M., (2014), Optimization of a Distributed Cogeneration System with solar district heating, Applied Energy, 124, 298-308.

Elsido C., Bischi A., Silva P., Martelli E., (2017), Two-stage MINLP algorithm for the optimal synthesis and design of networks of CHP units, Energy, 121, 403-426.

Fazlollahi S., Bungener S.L., Mandel P., Becker G., Maréchal F., (2014), Multi-objectives, multi-period optimization of district energy systems: I. Selection of typical operating periods, Computers and Chemical Engineering, 65, 54-66.

Gabrielli P., Gazzani M., Martelli E., Mazzotti M., (2018), Optimal design of multi-energy systems with seasonal storage, Applied Energy, 219, 408-424.

Gambarotta A., Morini M., Rossi M., Stonfer M., (2017), A library for the simulation of smart energy systems: The case of the campus of the University of Parma, Energy Procedia, 105, 1776-1781.
Kotzur L., Markewitz P., Robinius M., Stolten D., (2018), Impact of different time series aggregation methods on optimal energy system design, Renewable Energy, 117, 474-487.

Lahdelma R., Hakonen H., (2003), An efficient linear programming algorithm for combined heat and power production, European Journal of Operational Research, 148, 141-151.

RSE, (2009), Definition of indicators and classes of energy requirements of the different energy consumption centers in the educational buildings - energy consumption of primary and secondary schools, (in Italian), Report by RSE (Ricerca Sistema Elettrico), On line http://www.enea.it/it/Ricerca_sviluppo/documenti/rice rca-di-sistema-elettrico/governance/rse119.pdf.

Skoplaki E., Palyvos J.A., (2009), On the temperature dependence of photovoltaic module electrical performance: A review of efficiency/power correlations, Solar Energy, 83, 614-624.

SDH, (2012), Solar district heating guidelines: Collection of fact sheets, Report, Solar District Heating, On line at: http://solar-district heating.eu/Portals/0/Factsheets/SDH-WP3-D31D32_August2012.pdf.

Turton R., Bailie R.C., Whiting W.B., Shaeiwitz J.A., (2008), Analysis, Synthesis and Design of Chemical Processes, 3rd Edition, Prentice Hall International Series, Upper Saddle River.

Weber C., Maréchal F., Favrat D., (2007), Design and optimization of district energy systems, Computer Aided Chemical Engineering, 24, 1127-1132.

Yang Y., Zhang S., Xiao Y., (2015), Optimal design of distributed energy resource systems coupled with energy distribution networks, Energy, 85, 433-448.

Yokoyama R., Hasegawa Y., Ito K., (2002), A MILP decomposition approach to large scale optimization in structural design of energy supply systems, Energy Conversion and Management, 43, 771-790.

Yokoyama R., Ito K., (2006), Optimal design of gas turbine cogeneration plants in consideration of discreteness of equipment capabilities, Journal of Engineering for Gas Turbines and Power, 128, 336-343.

Zatti M., Gabba M., Rossi M., Balestrieri G., Gambarotta A., Morini M., Martelli E., (2018), A Systematic Approach for the Selection of the Typical and Extreme Days for the Optimal Design of Multi Energy Systems, Proc. ECOS 2018 - the 31st Int. Conf. on Efficiency, Cost, Optimization, Simulation and Environmental Impact of Energy Systems, Guimaraes, Portugal.

Web sites:

www.efficity-project.it

https://www.ibm.com/analytics/cplex-optimizer

http://www.gurobi.com 